\title{
Congenital Alveolar Capillary Dysplasia and New Associations: A Case Series with a Report of New Associations and Literature Review
}

\author{
Nandyal RR ${ }^{1 *}$, Parham $D^{2}$, Yu $Z^{3}$ and Escobedo $\mathbf{M}^{1}$
}

${ }^{1}$ Department of Pediatrics, Neonatology Section, Oklahoma University Health Sciences Center (OUHSC), USA

${ }^{2}$ Department of Anatomic Pathology, University of Southern California (USC), Los Angeles, CA, USA

${ }^{3}$ Department of Pathology, Oklahoma University Health Sciences Center (OUHSC), Oklahoma City, OK, USA

\begin{abstract}
Congenital Alveolar capillary dysplasia with misalignment of the pulmonary veins (ACD-MPV) is a rare and a lethal cause of neonatal respiratory failure and severe hypoxemia, secondary to persistent pulmonary hypertension (PPHN). It is refractory to all standard medical therapies including High Frequency Ventilation (HFV), inspired Nitric Oxide (iNO), and Extracorporeal Membrane Oxygenation (ECMO). According to the Online Mendelian Inheritance in Man (OMIM), it is caused by heterozygous mutation in the FOXF1 gene on chromosome 16q24. Newer study has suggested that two other genes can cause (ESRP1) or function as modifiers (PLXNB2) of the ACDMPV phenotype. Most reported cases of ACD-MPV had multiple congenital non-lethal anomalies. Here, we report six cases of autopsyproven ACD-MPV from a single institution during a seven year period. Medical information was obtained from the electronic medical records. Pathology slides were read and confirmed by pediatric pathologists of two different university hospitals. Novel findings include an association with previously undescribed congenital anomalies and a sibling with congenital alveolar dysplasia without capillary dysplasia. All patients presented in the newborn period, with severe hypoxemia and echocardiogram (Echo)-confirmed PPHN. The vast majority of ACDMPV cases continue to be diagnosed by autopsy, after the infants have been subjected to extreme degree of intensive care. ACD-MPV needs to be considered as a diagnostic possibility when ECMO fails.
\end{abstract}

Keywords: Alveolar capillary dysplasia; Diffuse lung disease in infancy; Children's interstitial lung disease (ChILD); Irreversible pulmonary hypertension

\section{Introduction}

Congenital alveolar capillary dysplasia with misalignment of the pulmonary veins (ACD-MPV) is a rare and a lethal cause of neonatal respiratory failure and severe hypoxemia. It usually presents shortly after birth or within 48 hours of life. The underlying persistent pulmonary hypertension (PPHN) is refractory to all standard medical therapies including High Frequency Ventilation (HFV), inspired Nitric Oxide (iNO), and Extracorporeal Membrane Oxygenation (ECMO) [1,2]. According to the Online Mendelian Inheritance in Man (OMIM), it is caused by a heterozygous mutation in the FOXF1 gene on chromosome 16q24 [3]. Newer study has suggested that two other genes can cause (ESRP1) or function as modifiers (PLXNB2) of the ACD-MPV phenotype [4].

The vast majority of reported ACD-MPV cases were diagnosed by autopsy, only after the infants underwent extremely sophisticated and complex neonatal intensive care, despite availability of other rarely utilized diagnostic modalities, including lung biopsy. Most of them had multiple congenital non-lethal anomalies [5] involving gastrointestinal (GI), cardio-vascular (CV), respiratory, ophthalmic, urogenital, and skeletal systems. We also provided a review of literature on ACD-MPV in the discussion part of this article.

\section{Materials and Methods}

Here, we report six cases of autopsy proven (unrestricted) ACDMPV from a single institution during a seven year period (January 2007 to January 2013). All of them received care at a Level IV Neonatal intensive care unit (University based Children's Hospital). Neonatology electronic medical records and verbal communication by Neonatology team members were the sources for the medical information. Pathology slides (autopsy specimens) of all cases were read by at least one pediatric pathologist at our Institution. And, all of those slides were also reviewed by a pediatric pathologist at another University. We also report a sibling of case number 3 with ACD-MPV that had congenital alveolar dysplasia without capillary dysplasia. A literature search was done using PubMed, OVID and Google Scholar and compared findings of our series to the previously reported cases. Institutional Review Board (IRB) for the Protection of Human Subjects gave a waiver, as our study did not meet the criteria for human subjects research.

\section{Results}

All of our six patients presented in the newborn period, with severe hypoxemia and echocardiogram (Echo)-confirmed PPHN and expired within a month (range 2 hours to 30 days). We had 4 girls and 2 boys. ECMO was tried unsuccessfully, early ( $<7$ days of age) on 3 infants and later (at 3 weeks of age) on one infant. ECMO could not be offered to the other two infants (expired at less than 5.5 hours). Except for the sibling of our patient number 3 , none had ante-mortem lung biopsy.

In addition to finding ACD-MPV, we noted various previously described abnormalities in our group of infants (Table 1). These included minor facial dysmorphic features, cardiac anomalies (mainly ventricular (VSD) and atrial septal defects (ASD), patent ductus arteriosus (PDA) and patent foramen ovale (PFO), pulmonary

*Corresponding author: Nandyal RR, Clinical Associate Professor, Neonatology Section, Department of Pediatrics, Oklahoma University Health Sciences Cente (OUHSC), Oklahoma City, OK 73104, USA, Tel: 14052715215; E-mail: Raja-Nandyal@ouhsc.edu

Received March 06, 2017; Accepted March 20, 2017; Published March 31, 2017

Citation: Nandyal RR, Parham D, Yu Z, Escobedo M (2017) Congenital Alveolar Capillary Dysplasia and New Associations: A Case Series with a Report of New Associations and Literature Review. Med Rep Case Stud 2: 129. doi: 10.4172/2572 5130.1000129

Copyright: () 2017 Nandyal RR, et al. This is an open-access article distributed under the terms of the Creative Commons Attribution License, which permits unrestricted use, distribution, and reproduction in any medium, provided the original author and source are credited. 
Citation: Nandyal RR, Parham D, Yu Z, Escobedo M (2017) Congenital Alveolar Capillary Dysplasia and New Associations: A Case Series with a Report of New Associations and Literature Review. Med Rep Case Stud 2: 129. doi: 10.4172/2572-5130.1000129

Page 2 of 6

\begin{tabular}{|c|c|c|c|c|c|}
\hline System & Total & Case Number & $\begin{array}{l}\text { Previously Described } \\
\text { Anomalies }\end{array}$ & Case Number & New Associations \\
\hline \multirow[t]{5}{*}{ Cardio-vascular } & 5 & $1,2,6$ & Patent ductus arteriosus & 6 & $\begin{array}{l}\text { Partial anomalous pulmonary venous return } \\
\text { (PAPVR) draining into right atrium (RA) }\end{array}$ \\
\hline & & $1,2,6$ & Patent foramen ovale & 3 & $\begin{array}{l}\text { Azygos continuation of Inferior Vena cava } \\
\text { into Superior venacava, drainage of renal } \\
\text { and adrenal veins to hepatic vein (HV), HV } \\
\text { continuation to RA }\end{array}$ \\
\hline & & & & & Pulmonary atresia (with membranous VSD \\
\hline & & 5,6 & Ventricular septal defect (VSD) & 5 & \\
\hline & & 5 & Atrial septal defect & & \\
\hline \multirow[t]{3}{*}{ Skeletal } & \multirow[t]{2}{*}{2} & \multirow[t]{2}{*}{6} & \multirow[t]{2}{*}{$\begin{array}{l}\text { Right tibial hypoplasia- right short } \\
\text { extremity }\end{array}$} & \multirow[t]{2}{*}{1} & $\begin{array}{l}\text { Bilateral humeral hypoplasia, absent radii and } \\
\text { thumbs, } 3 \text { digit hands }\end{array}$ \\
\hline & & & & & $\begin{array}{l}\text { Scoliosis, genu recurvatum, club foot, thoracic } \\
\text { hemivertebrae, spina bifida occulta, abnormal } \\
\text { ribs, tethered cord, finger like appendage at the } \\
\text { right sacro-coccygeal area }\end{array}$ \\
\hline & & & & 6 & \\
\hline \multirow[t]{4}{*}{ Chest- pulmonary } & 3 & 6 & Left diaphragmatic eventration & & \\
\hline & & 6 & Uni-lobate lungs & & \\
\hline & & 2 & Lymphangiectasia & & \\
\hline & & 1 & Pulmonary hypoplasia & & \\
\hline Genito-urinary & 1 & & & 6 & $\begin{array}{l}\text { Mullerian duct malformation, left Fallopian } \\
\text { tube agenesis, hyposplasia of left ovary } \\
\text { (suspect MURCS association including thoracic } \\
\text { hemivertebrae) }\end{array}$ \\
\hline \multirow[t]{2}{*}{ Gastro-intestinal } & 1 & 6 & Omphalocele with herniation of liver & & \\
\hline & & 6 & Malrotation-volvulus & & \\
\hline Hematological & 2 & & & 6 & $\begin{array}{l}\text { Hepatic vein thrombosis (suspect Budd-Chiari } \\
\text { syndrome); }\end{array}$ \\
\hline \multirow[t]{4}{*}{ Multi-system-Hydrops } & 5 & & & 2,3 & $\begin{array}{l}\text { Hydrops (peri-cardial effusion, pleural effusion, } \\
\text { ascites, edema) }\end{array}$ \\
\hline & & & & 1 & Pleural effusion \\
\hline & & & & 6 & Ascites \\
\hline & & & & 4 & Anasarca \\
\hline \multirow[t]{4}{*}{ Dysmorphic Features } & 2 & 1 & Low set ears & 1 & Atresia of both auditory canals \\
\hline & & 1 & Flat nasal bridge & 1 & Hypo-plastic malformed pinnae \\
\hline & & & & 1 & Wider sagittal suture \\
\hline & & 3 & Hypertelorism & 3 & Broad nasal bridge with a crease \\
\hline
\end{tabular}

Table 1: ACD-MPV Associations (notes in our series).

hypoplasia, unilobate lungs, polysplenia (heterotaxy), pulmonary lymphangiectasia, diaphragmatic eventration, omphalocele, intestinal malrotation, renal anomalies (hydronephrosis and hydroureters), hypoplasia of ovaries, and tibial hypoplasia. Novel findings include an association with previously undescribed congenital anomalies (Table 1), such as absent auditory canals, skeletal anomalies including hypoplasia of humeri, absent radius and thumbs, club foot, scoliosis, genu recurvatum, vertebral and rib anomalies and spina bifida occulta, tethered cord, venous anomalies including inferior venal cava (IVC) continuation into the azygos vein, renal and adrenal veins draining into hepatic vein, hepatic vein thrombosis (suspected Budd-Chiari syndrome), genitourinary anomalies including mullerian duct malformations and agenesis of fallopian tube (suspected MURCS association), hydrops fetalis, isolated pleural effusions, pericardial effusion, and ascites.

\section{Case Reports}

\section{Case 1}

This term 2.5 kilogram $(\mathrm{kg})$ female infant was born vaginally to a 14 year old primigravida colonized with group B streptococcus (GBS). Maternal history was positive for prolonged rupture of membranes (PROM) of 35 days and use of alcohol and drugs including nicotine (cigarettes). She had low Apgar scores. She was noted to have dysmorphic features including slightly wider sagittal suture, absent ear canals, hypoplastic and malformed pinnae, and a flattened nasal bridge. Multiple skeletal-limb anomalies included hypoplastic arms with bilateral shortened humeri, absent radii, absent thumbs, and three digit hands. Shortly after birth, she developed persistent hypoxemia secondary to Echo-confirmed severe PPHN. She rapidly developed profound systemic hypotension and bilateral pneumothoraces that required chest tubes. She expired within $5 \frac{1}{2}$ hours of age, despite aggressive management including high frequency oscillatory ventilation (HFOV), iNO, vasopressors, and systemic corticosteroids. ECMO could not be offered.

Autopsy revealed, PDA, PFO, and pulmonary hypoplasia (total lung weight was 16.54 grams; normal $44.6+/-22.7$ grams). Of particular note were misalignment of pulmonary veins, abnormal alveolar capillaries, and intra-parenchymal muscular arteries (Figure 1). Other salient findings included mild hyaline membrane disease, small pleural effusions, alveolitis, myositis of psoas, and markedly decreased subcutaneous fat.

\section{Case 2}

This term large for gestational age male infant, with a birth weight of 


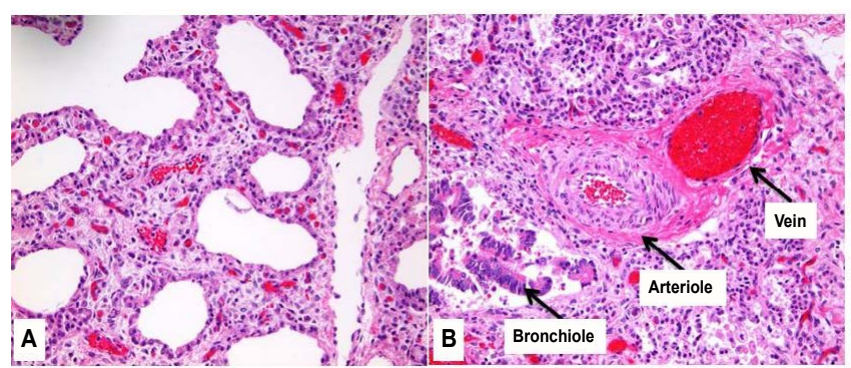

Figure 1: Characteristics histological features of ACD with misalignment pulmonary vein. (A) Thickened alveolar walls with centrally located alveola capillaries that do not make contact with alveolar epithelium. (B) Anomalously situated pulmonary vein running alongside pulmonary arteriole and sharing the same adventitial sheath.

$4.78 \mathrm{~kg}$, was delivered to a 30 year old primigravida by caesarian section (C-section) because of suspected hydrops fetalis. Apgar scores were 1 and 7 at 1 and 5 minutes of age. There were no external dysmorphic features. The infant's problem list included acute respiratory failure, persistent hypoxemia since birth, generalized edema, pleural effusions, pericardial effusion, ascites, systemic hypotension, anemia, PFO, PDA, suspected sepsis, disseminated intravascular coagulation (DIC), and Echo-confirmed PPHN. Treatment with packed red blood cell (PRBC) transfusion, vasopressors, HFOV, iNO, and ECMO was unsuccessful. The infant was allowed natural death (AND) at 9 days of age.

Autopsy findings included atrial septal defect (ASD), PDA, bilateral pleural effusions (chylothoraces), lymphangiectasia, pericardial effusion, and ascites. Of particular note were misalignment of pulmonary vessels, arterial muscular hyperplasia, and alveolar interstitial widening.

\section{Case 3}

This preterm male infant was born at $32+2 / 7$ weeks to a 24 year old gravida 3, para 2 mother, who was positive for IgG antibody for cytomegalovirus. Significant neonatal findings included a birth weight of $4.02 \mathrm{~kg}$, anemia and thrombocytopenia, and low Apgar scores. Examination showed a broad, flat, creased nasal bridge, hypertelorism, blueberry muffin skin nodules, and hepatosplenomegaly. Placental pathology revealed findings consistent with erythroblastosis fetalis. Echo confirmed severe PPHN. ECMO was not indicated. Therapy with HFOV and iNO was unsuccessful, and the infant expired at 17 days of age.

Autopsy showed azygos continuation of the inferior vena cava into the superior vena cava, hepatic vein continuation to right atrium, drainage of renal and adrenal veins into the hepatic vein, hydrops fetalis, pericardial effusion, chylous pleural effusions, ascites, foamy pulmonary interstitial cells, and extramedullary hematopoiesis (EMH) of kidneys. Particularly pertinent findings included misalignment of pulmonary vessels, arterial muscular hyperplasia, alveolar interstitial widening, and lymphangiectasia.

The sibling of case 3 was a preterm female infant born at 33 weeks gestation with a birth weight of $2.2 \mathrm{~kg}$ and low Apgar scores. She had low set ears, a high arched palate, and a malformed philtrum. She developed respiratory distress and severe hypoxemia. Echo showed PFO, PDA, and PPHN. The infant's respiratory status fluctuated widely between improvements and worsening. Chromosomal lymphocyte karyotyping (46, XX) and fluorescence in situ hybridization (FISH) for Chromosomes X, Y, 13, 18 and 21 were normal. Lung biopsy performed at 1 month of age showed alveolar growth abnormalities with interstitial thickening and focal muscularization of alveolar septa, but a definitive diagnosis of ACD-MPV could not be made. FOXF1 gene mutation testing was negative. The hospital course was complicated by bronchopulmonary dysplasia, PFO, PDA, PPHN, systemic hypotension, sepsis, pneumonia, anemia, thrombocytopenia, ascites, liver dysfunction and cholestasis. The infant expired at 4 months of age.

Autopsy findings included a weight of $5.88 \mathrm{~kg}$ and acute bronchopneumonia. Of particular note were diffuse developmental abnormalities with changes suggestive of congenital alveolar dysplasia, with arrested lobular development at the saccular stage, medial hypertrophy of small pulmonary arteries, and extension of arterial smooth muscle into normally non-muscularized alveolar wall vessels. Pulmonary veins were normally positioned but showed dilation and congestion. Pulmonary reactive changes included uniform alveolar epithelial hyperplasia.

\section{Case 4}

This term female was born to a 25 year old primigravida. Birth weight was $3.12 \mathrm{~kg}$, and had normal Apgar scores. There were no dysmorphic features. Shortly after birth, the infant developed severe respiratory distress and persistent hypoxemia, and Echo confirmed PPHN. Problems also included marked generalized edema, acute renal failure, multiple intracranial hemorrhages, seizures, and ischemia and gangrene of all digits. Management with iNO, HFOV, and ECMO was unsuccessful, and she expired at 1 month of age.

Salient autopsy findings included misalignment of pulmonary veins, abnormal alveolar airspaces, and intra-parenchymal muscular arteries. Other autopsy findings were pulmonary infarction, pulmonary hemorrhage, diffuse hemorrhagic medullary necrosis of kidneys, diffuse hemorrhagic necrosis of ovaries, splenic infarction, right ventricular hypertrophy (RVH), and focal acute bronchopneumonia.

\section{Case 5}

This late preterm female infant with a birth weight of $2.7 \mathrm{~kg}$, was born at $36+5 / 7$ weeks, to a 32 year old primigravida, with type 2 diabetes mellitus. Apgar scores were low. No external dysmorphic features were documented. The infant presented with severe hypoxemia, and Echo-confirmed PPHN. Echo also revealed pulmonary atresia, severe myocardial dysfunction, and no ventricular septal defect (VSD). Severe anemia (Hemoglobin $5.3 \mathrm{gm} / \mathrm{dl}$ ) and thrombocytopenia (platelet count of $17,000 / \mathrm{cm}^{3}$ ) were also noted. Treatment with HFOV and iNO was unsuccessful. The infant expired at 2 hours of life.

Autopsy revealed generalized ecchymosis, pulmonary atresia with membranous VSD, ASD, PFO, RVH, sub-galeal hematoma, and avulsion of umbilicus. Of particular note were misalignment of pulmonary vessels, underdeveloped alveolar spaces, and thickened pulmonary interstitium. Placental examination revealed stage I acute chorioamnionitis, moderate decidual vasculopathy, and increased syncytial knots.

\section{Case 6}

This was a 39 week small for gestational age (SGA) female infant, with a birth weight of $2.2 \mathrm{~kg}$, born by C-section to a 26 year old gravida 3 , para 3 mother with history of gestational hypertension. An antenatal ultrasound examination done at 22 weeks plus 3 days of age showed multiple fetal anomalies including a large omphalocele, kyphoscoliosis and deformed lower extremities. Apgar scores were normal. Initial examination revealed no significant facial dysmorphic features but showed a large omphalocele, thoracolumbar kyphoscoliosis, short 
right lower extremity with genu recurvatum, left club foot, a fingerlike at the sacro-coccygeal appendage, and a small pseudo-scrotal mass with minimal rugae located at the right posterior costovertebral area.

Chest radiographs showed abnormalities of thoracic ribs and scoliosis. Echo showed severe PPHN, dilation of right atrium and right ventricle, moderate sized PFO, PDA, and membranous (infracristal) VSD. Also noted were dilated hepatic veins with increased flow. Left pulmonary veins were normal and Right pulmonary veins were not well visualized. Head ultrasound showed grade I intraventricular hemorrhage (IVH). Spinal ultrasound exam showed multi-level segmental anomalies, possible tethered cord, and a neuropore suggesting myelo-meningocele versus other complex abnormalities. Radiographs of lower extremities showed left subtotal tibial aplasia with deformity, suggestive of distal ectromelia. Renal ultrasonography showed a horseshoe kidney with mild central pelviectasis. Chromosomal studies and FISH for chromosomes X, Y, 13, 18 and 21 were normal. The infant was relatively "stable" for three weeks with capillary $\mathrm{pH}$ above 7.30 with oxygen saturations in mid to high 90s, on high flow nasal cannula with $\mathrm{FiO}_{2}$ ranging between 0.4 and 0.6. Therapy included diuretics, sildenafil, inhaled nitric oxide (iNO), and vasopressors. Later the infant deteriorated rapidly. She did not respond to high frequency ventilation. ECMO was tried unsuccessfully. Within 3 days of ECMO therapy, the infant deteriorated rapidly and died at 26 days of age.

Autopsy showed a large omphalocele $(7 \times 7 \mathrm{~cm})$ with liver herniation, volvulus (involving right colon and ileum), ascites, malformation of liver and spleen, abnormal location of left adrenal gland, hepatic venous thrombosis (suspected Budd-Chiari syndrome), left diaphragmatic eventration, Mullerian duct malformation complex (left fallopian tube agenesis, hypoplastic uterus and ovaries, right ovary with cystic follicles and left ovarian hypoplasia- suspected MURCS association), partial anomalous venous return with drainage into right atrium, $\mathrm{PFO}, \mathrm{ASD}, \mathrm{PDA}$, and unilobate right lung. Of particular note were hypoplastic arteries without communication with alveoli and alveolar capillary dysplasia. Additional findings included lower lumbar spina bifida occulta, tethered cord, multiple thoracic hemivertebrae, severe scoliosis, right tibial hypoplasia, right talipes equinovarus, and common renal capsule at the lower poles with separate parenchyma).

\section{Discussion}

Diffuse pulmonary developmental disorders commonly seen in early neonates include acinar dysplasia, congenital alveolar dysplasia (CAD), and alveolar capillary dysplasia with misalignment of pulmonary veins (ACD-MPV) [6]. Acinar dysplasia denotes an extreme form of pulmonary hypoplasia showing airway structures with little or no acinar structures and no alveoli. As a result, most affected infants die within the first few hours after birth. Congenital alveolar dysplasia is a less well-known but likely somewhat more common entity that shows an arrest in lung development later in the canalicular or early saccular stage, but without misalignment of pulmonary vein. Affected infants are usually term and develop respiratory failure, sometimes accompanied by cardiac insufficiency and pulmonary hypertension in their early neonatal life. These patients may survive for a longer period of time with ventilator support, nitric oxide, and/or extracorporeal membrane oxygenation, but cannot be weaned from these supports. ACD-MPV is the best known of these 3 diffuse pulmonary developmental disorders.

ACD-MPV is a rare and lethal cause of diffuse childhood interstitial lung disease (ChiLD) [7]. The cardinal features of interstitial lung diseases are markedly defective gas exchange, restrictive lung physiology, and diffuse involvement of both lungs. ACD-MPV is the leader of a heterogeneous group of such disorders, noted to have defective development of the alveoli, distal airspaces and abnormal lung vasculature. It almost always presents with intractable hypoxemia secondary to neonatal persistent pulmonary hypertension (PPHN), refractory to therapy [3]. Mechanisms linking abnormal lung vasculature with severe hypoxemia in ACD-MPV are still unclear $[2,5]$.

\section{Historical perspective}

In 1948, MacMahon [3] was first to describe the condition congenital alveolar dysplasia, that was noted in three full-term infants who died within 2 days of life, from intractable hypoxemia following severe respiratory distress since birth. At autopsy, microscopy of fresh lung tissue revealed an excess of interstitial tissue that was rich in capillaries, surrounding a few isolated and sometimes over distended pulmonary alveoli. Other listed anomalies include an atrial septal defect, and hypoplasia of the brain in one infant, and an accessory spleen in the other two, as well as bilateral uretero-pelvic junction constriction in one of the infants. In 1981, Janney and her team $[1,7]$, designated this disorder of persistent fetal circulation with abnormalities of pulmonary vascular development, as "congenital alveolar capillary dysplasia." They noted that the "failure of the formation and ingrowth of alveolar capillaries led to the absence of normal air-blood barriers. Anomalous veins were noted in the broncho-vascular bundles, during the post mortem examination of the lungs".

Since then, approximately 120 cases have been reported worldwide. Currently, in the vast majority of cases, the definitive diagnosis of ACD-MPV has been obtained from the histological examination of lung tissue on autopsy and very rarely from ante-mortem lung biopsy, which is a rarely considered option in a critically ill and unstable neonate. It is also possible that the diagnosis presumably could be missed by pathologists, who are unfamiliar with this disorder. Thus, the precise incidence of this disorder cannot be clearly ascertained.

\section{Clinical picture and diagnosis}

Typically like our case series, these infants present in the newborn period with persistent hypoxemia and central cyanosis with fairly normal chest radiographs. Our female to male ratio was $2: 1$. A male predominance has been noted minimally, in other case reports [5]. They may or may not have any dysmorphic features. Echo reveals evidence of severe persistent pulmonary hypertension (PPHN). This condition is universally fatal without lung transplantation. As in our case series, aggressive therapy with of HFOV and iNO will not help except for "buying time for lung transplant".

The only current diagnostic modality is open lung biopsy [8-10] Despite its availability, most cases continue to be diagnosed by autopsy only. We had a sibling of case number 3 that had ante-mortem lung biopsy which showed evidence of congenital alveolar dysplasia with no involvement of capillaries. Based on the treatment and care of 3 infants with ACD-MPV, Hintz et al. [11] suggested cardiac catheterization and biopsy as an alternative to transthoracic lung biopsy, but this procedure is not well accepted because of its invasiveness and potential for further deterioration. Very recently, there have been a couple of reports of ACD-MPV diagnosed prenatally and confirmed postnatally by lung biopsy. Prothro et al. presented a presumptive prenatal diagnosis of ACD-MPV based on chorionic villus sampling of a FOXF1 mutation in a fetus with extra-pulmonary anomalies often associated with ACDMPV [12].

\section{Late Presenters and long-term survivors}

The vast majority of these infants die in the neonatal period. Only 
one infant in our series with ACD-MPV lived up to 30 days. Survival for up to 101 days was reported in an infant with ACD-MPV proven by open lung biopsy at 23 days of age. Inspired Nitric oxide was offered to improve the prospect of survival until lung transplantation could be performed [13]. Kodama Y et al. described a patient with alveolar capillary dysplasia who survived for 237 days of age despite associated severe refractory pulmonary hypertension, complicated by doubleoutlet right ventricle and duodenal atresia [14]. A couple more reports of infants presenting with clinical features of ACD-MPV beyond the neonatal period have been described in the literature. Shankar et al. [15] reported ACD-MPV in a 7 week old girl and Ahmed S et al. [16] reported ACD-MPV in a 7 month old girl.

\section{Histopathology}

ACD-MPV reveals failure of formation of alveolar capillaries and their ingrowth. These capillaries do not make contact with alveolar epithelium. Other histopathological findings include medial muscular thickening of small pulmonary arterioles with muscularization of the intra-acinar arterioles, thickened alveolar walls, and anomalously situated pulmonary veins, running alongside pulmonary arterioles and sharing the same adventitial sheath [17]. Other less common findings include a reduced number of alveoli and a patchy distribution of the histopathologic changes [2].

\section{Molecular genetics}

ACD-MPV is caused by heterozygous mutation in the FOXF1 gene on chromosome 16q24. Newer study has suggested that two other genes could be causative (ESRP1) or function as modifiers (PLXNB2) of the ACD-MPV phenotype [3,4]. Stankiewicz et al. [18] identified 6 overlapping microdeletions encompassing the FOX transcription factor gene cluster on chromosome 16q24.1-q24, all but 1 of which included the FOXF1 gene. In contrast to the association of point mutations in FOXF1 with bowel malrotation, they also noted that microdeletions of FOXF1 were associated with hypoplastic left heart syndrome and gastrointestinal atresias. A p.Arg86Pro mutation in the FOXF1 (Forkhead Box-F1) gene was reported in a case with ACDMPV associated with coloboma iridis and hemihypertrophy [19].

Pasutto et al. noted, in two unrelated consanguineous families with malformation syndromes that included anophthalmia and distinct eyebrows [20]. One family had ACD or complex congenital heart defect and the second family had diaphragmatic hernia. Both had linkage to a common locus on chromosome 15 , as identified by homozygosity mapping. Pathogenic homozygous mutations were identified in STRA6, a member of a large group of "stimulated by retinoic acid" genes encoding novel transmembrane proteins, transcription factors, and secreted signaling molecules or proteins of largely unknown function.

Shehata et al. described what appears to be the first case of ACDMPV associated with trisomy 21. Other complications included endocardial cushion defect, hypothyroidism, and intrauterine growth restriction. This boy eventually died at 3 months of age from cardiac dysfunction, septicemia, and multi-organ failure [21]. Also noted were facial dysmorphic features and other cardiac anomalies. Interestingly, several of the associated anomalies commonly noted with Trisomy 21 are also seen in patients with ACD without Trisomy 21 [22].

\section{Associated anomalies}

OMIM lists [3] other additional features of ACD-MPV including multiple congenital anomalies affecting the cardiovascular, gastrointestinal, genitourinary, and musculoskeletal systems, as well as disruption of the normal right-left asymmetry of intrathoracic or intra- abdominal organs. Sen and his associates reported anomalies other than those associated with the microscopic pulmonary phenotype of ACD in 18 out of their 24 study subjects [17]. Genito-urinary anomalies were reported in 6 infants (hydronephrosis / hydroureter, marked bladder hypertrophy, urethral atresia, and small asymmetric ovaries), cardiac anomalies were reported in 5 infants (Atrial septal defect, coarctation of aorta, pulmonary artery hypoplasia, mitral and tricuspid valve malformations, $\mathrm{A}-\mathrm{V}$ canal, hypoplastic left heart, and cor-triatrium) and Intestinal malrotation was noted in 3 infants. Other GI anomalies were colorectal Hirschprung's, and imperforate anus. Three infants had abnormal lobation of lungs. They also reported cavernous hemangioma of the liver, absence of gall bladder, butter fly vertebra (?VATER), Sturge-Weber syndrome and single umbilical artery.

Other studies reported other associated anomalies, including esophageal atresia with trachea- esophageal fistula [23], coloboma iridis with hemihypertrophy [19], vascular ring [24], intestinal atresia [25], annular pancreas [26], anorectal anomaly [27], pneumothorax [28], duodenal stenosis [26], duodenal atresia [29,30], omphalocele [31], Cystic adenomatoid malformation [32], microphthalmia [33], bilateral tibial agenesis [34], anterior segmental dysgenesis of the eye [35], and phocomelia [36].

\section{Familial cases}

In approximately in $10 \%$ of reported cases [5,7], other family members including siblings $[36,37]$ were affected, which is suggestive of an autosomal recessive inheritance pattern. Recently, there was a case report of two siblings [38], with two years of difference, from different fathers; one of them was a first-degree and the other a second-degree cousin of the mother. Both patients were full-term babies born apparently without malformations and at approximately 35 hours of age presented severe respiratory failure due to pulmonary hypertension. The outcome was fatal in both cases and at autopsy, ACD-MPV was diagnosed. Sen et al. described a family with five out of six children affected with ACD-MPV [39]. DNA analysis identified a missense mutation in the FOXF1 gene. The same variant is also present as a de novo mutation in the mother and came from her paternallyderived chromosome 16. The two tested affected siblings share the same chromosome 16 haplotype (inherited from their maternal grandfather). Their single healthy sibling has inherited a different chromosome 16 haplotype from the maternal grandmother. These results strongly suggest the possibility of paternal imprinting of FOXF1 as responsible for the recurrence of this disorder [39].

\section{Conclusion}

ACD-MPV is a very rare and lethal cause of neonatal respiratory failure and severe hypoxemia, secondary to severe PPHN, which is refractory to standard therapies like HFOV, iNO, and ECMO. Despite the feasibility of open lung biopsy in making an early diagnosis, this is rarely done. The vast majority of ACD-MPV cases continue to be diagnosed by autopsy, after the infants have been subjected to extreme degree of intensive care. ACD-MPV needs to be considered as a diagnostic possibility when ECMO fails. Trying an algorithm approach as suggested by Michalskya et al. [40], that includes offering open lung biopsy as an alternative approach to parents, at a stage when medical therapy and/or ECMO are failing in the management of atypical PPHN, needs to be considered.

\section{Acknowledgements}

This case series was previously presented as a poster presentation at the 
Citation: Nandyal RR, Parham D, Yu Z, Escobedo M (2017) Congenital Alveolar Capillary Dysplasia and New Associations: A Case Series with a Report of New Associations and Literature Review. Med Rep Case Stud 2: 129. doi: 10.4172/2572-5130.1000129

Pediatric Academic Societies (PAS) meeting on April 28th 2015, at San Diego $\mathrm{CA}$. The opinions expressed are those of the authors and do not necessarily reflect those of the OUHSC or USC. The authors would like to acknowledge the valuable contribution of their exceptional expertise on this subject of two nationally well-known Pathologists, Dr. J. Thomas Stoker of the department of Pathology, Uniformed Services University of the Health Sciences, Bethesda, MD and Dr. Claire Langston of Department of Pathology, Baylor College of Medicine and Texas Children's Hospital, Houston, TX. Pathology slides of six patients were reviewed by Dr. Stoker and of another infant was reviewed by Dr. Langston. We would also like to recognize the guidance and suggestions received from our departmen colleagues, Dr. Edgardo Szyld, Dr. Gene Halford in the preparation and review of the manuscript. Also, acknowledge our Neonatal Fellowship graduate Dr. Jami Lewis, for her contribution of a case report, from the same institution.

\section{References}

1. Janney CG, Askin FB, Kuhn C (1981) Congenital alveolar capillary dysplasiaan unusual cause of respiratory distress in the newborn. Am J Clin Pathol 76: 722-727.

2. Galambos C, Sims-Lucas S, Ali N, Gien J, Dishop MK, et al. (2015) Intrapulmonary vascular shunt pathways in alveolar capillary dysplasia with misalignment of pulmonary veins. Thorax 70: 84-85.

3. Alveolar Capillary Dysplasia with Misalignment of Pulmonary Veins; ACDMPV.

4. Szafranski $P$, Gambin T, Dharmadhikari AV, Akdemir KC, Jhangiani SN, et al. (2016) Pathogenetics of alveolar capillary dysplasia with misalignment of pulmonary veins. Hum Genet 135: 569-586.

5. Miranda J, Rocha G, Soares H, Vilan A, Brandão O, et al. (2013) Alveolar capillary dysplasia with misalignment of pulmonary veins (ACD/MPV): A case series. Case reports in critical care.

6. Langston C, Dishop MK (2009) Diffuse lung disease in infancy: a proposed classification applied to 259 diagnostic biopsies. Pediatr Dev Pathol 12: 421-437.

7. Bishop NB, Stankiewicz P, Steinhorn RH (2011) Alveolar capillary dysplasia. Am J Respir Crit Care Med 184: 172-179.

8. Deshmukh H, Lioy J (2014) The use of early lung biopsy in detection of fatal pulmonary disease in the neonate. J. Pediatr 164: 934-936.

9. Inwald D, Brown K, Gensini F, Malone M, Goldman A (2004) Open lung biopsy in neonatal and paediatric patients referred for extracorporeal membrane oxygenation (ECMO). Thorax 59: 328-333.

10. Eulmesekian P, Cutz E, Parvez B, Bohn D, Adatia I (2005) Alveolar capillary dysplasia: a six-year single center experience. J Perinat Med 33: 347-352.

11. Hintz SR, Vincent JA, Pitlick PT, Fineman JR, Steinhorn RH, et al. (1999) Alveolar capillary dysplasia: diagnostic potential for cardiac catheterization. J Perinatol 19: 441-446.

12. Prothro SL, Plosa E, Markham M, Szafranski $P$, Stankiewicz $P$, et al. (2016) Prenatal diagnosis of alveolar capillary dysplasia with misalignment of pulmonary veins. J Pediatr 170: 317-318.

13. Licht C, Schickendantz S, Sreeram N, Arnold G, Rossi R, et al. (2004) Prolonged survival in alveolar capillary dysplasia syndrome. Eur J Pediatr 163: 181-182.

14. Kodama Y, Tao K, Ishida F, Kawakami T, Tsuchiya K, et al. (2012) Long survival of congenital alveolar capillary dysplasia patient with NO inhalation and epoprostenol: effect of sildenafil, beraprost and bosentan. Pediatr Int 54: 923-926.

15. Shankar V, Haque A, Johnson J, Pietsch J (2006) Late presentation of alveolar capillary dysplasia in an infant. Pediatr Crit Care Med 7: 177-179.

16. Ahmed S, Ackerman V, Faught P, Langston C (2008) Profound hypoxemia and pulmonary hypertension in a 7-month-old infant: late presentation of alveolar capillary dysplasia. Pediatr Crit Care Med 9: e43-e46.

17. Sen P, Thakur N, Stockton DW, Langston C, Bejjani BA (2004) Expanding the phenotype of alveolar capillary dysplasia (ACD). J Pediatr 145: 646-651.

18. Stankiewicz P, Sen P, Bhatt SS, Storer M, Xia Z, et al. (2009) Genomic and genic deletions of the FOX gene cluster on 16q24.1 and inactivating mutations of FOXF1 cause alveolar capillary dysplasia and other malformations. Am J Hum Genet 84: 780-791.

19. Geddes GC, Dimmock DP, Hehir DA, Helbling DC, Kirkpatrick E, et al. (2015) A novel FOXF1 mutation associated with alveolar capillary dysplasia and coexisting colobomas and hemihyperplasia. J Perinatol 35: 155-157.

20. Pasutto F, Sticht H, Hammersen G, Gillessen-Kaesbach G, FitzPatrick DR, et al. (2007) Mutations in STRA6 cause a broad spectrum of malformations including anophthalmia, congenital heart defects, diaphragmatic hernia, alveolar capillary dysplasia, lung hypoplasia, and mental retardation. Am J Hum Genet 80: 550-560.

21. Shehata BM, Abramowsky CR (2005) Alveolar capillary dysplasia in an infant with trisomy 21. Pediatr Dev Pathol 8: 696-700.

22. McGaughran J, Souter DJ, Kuschel CA (2001) Alveolar capillary dysplasia with antenatal anomalies mimicking trisomy 21. J Paediatr Child Health 37: 85-86.

23. Razak A, Mohanty PK (2015) Alveolar Capillary Dysplasia as a Cause of Persistent Pulmonary Hypertension. IMSEAR 52: 984-986.

24. Bellamkonda-Athmaram V, Sulman CG, Basel DG, Southern J, Konduri GG, et al. (2014) Alveolar capillary dysplasia with multiple congenital anomalies and bronchoscopic airway abnormalities. J Perinatol 34: 326-328.

25. Nguyen L, Riley MM, Sen P, Galambos C (2013) Alveolar capillary dysplasia with misalignment of pulmonary veins with a wide spectrum of extrapulmonary manifestations. Pathol Int 63: 519-521.

26. Miranda J, Rocha G, Soares P, Morgado H, Baptista MJ, et al. (2013) A nove mutation in FOXF1 gene associated with alveolar capillary dysplasia with misalignment of pulmonary veins, intestinal malrotation and annular pancreas. Neonatology 103: 241-245.

27. Uhrikova Z, Matasova K, Jurko A Jr, Zibolen M (2011) Alveolar capillary dysplasia with anorectal anomaly. Indian Pediatr 48: 803-804

28. Roy PG, Patel P, Vayalakkad A, Bowker C, Lakhoo K (2007) Alveolar capillary dysplasia presenting as pneumothorax: a case report and review of literature. Pediatr Surg Int 23: 915-917.

29. Obata-Yasuoka M, Hamada H, Ohara R, Nakao A, Miyazono Y, et al. (2011) Alveolar capillary dysplasia associated with duodenal atresia: ultrasonographic findings of enlarged, highly echogenic lungs and gastric dilatation in a thirdtrimester fetus. J Obstet Gynaecol Res 37: 937-939.

30. Shimizu T, Fukuda T, Inomata S, Satsumae T, Tanaka M (2011) A nove association of alveolar capillary dysplasia, atypical duodenal atresia, and subglottic stenosis. J Anesth 25: 298-300.

31. Gerrits LC, De Mol AC, Bulten J, Van der Staak FH, Van Heijst AF (2010) Omphalocele and alveolar capillary dysplasia: a new association. Pediatr Crit Care Med 11: e36-e37.

32. Roeleveld PP, Martin J, Chow CW, Duke T (2008) A neonate with coexisting congenital cystic adenomatoid malformation of the lung and alveolar capillary dysplasia: a case report with review of literature. Pediatr Crit Care Med 9 : e10-e13.

33. Schirmer-Zimmerman H, Hammersen G, Scheuerlen W, Griese M, Brasch F, et al. (2006) CR3/108-Congenital alveolar capillary dysplasia with familiary microphthalmia. Paediatr Respir Rev 7 Suppl1: S326.

34. Witters I, Devriendt K, Moerman P, Caudron J, Van Hole C, et al. (2001) Bilateral tibial agenesis with ectrodactyly (OMIM 119100): further evidence for autosomal recessive inheritance. Am J Med Genet 104: 209-13.

35. Merchak A, Lueder GT, White FV, Cole FS (2001)Alveolar capillary dysplasia with misalignment of pulmonary veins and anterior segment dysgenesis of the eye: a report of a new association and review of the literature. J Perinatol 21 : 327-330.

36. Boggs S, Harris MC, Hoffman DJ, Goel R, McDonald-McGinn D, et al. (1994) Misalignment of pulmonary veins with alveolar capillary dysplasia: affected siblings and variable phenotypic expression. J Pediatr 124: 125-128.

37. Gutierrez C, Rodriguez A, Palenzuela S, Forteza C, Rossello JL (2000) Congenital misalignment of pulmonary veins with alveolar capillary dysplasia causing persistent neonatal pulmonary hypertension: report of two affected siblings. Pediatr Dev Pathol 3: 271-276

38. Benevides GN, Picciarelli de Lima P, Felipe-Silva A, Lovisolo SM, Andrello Gonçalves AM, et al. (2015) Recurrence of alveolar capillary dysplasia with misalignment of pulmonary veins in two consecutive Siblings. Autopsy Case Rep [Internet] 5: 21-27

39. Sen P, Gerychova R, Janku P, Jezova M, Valaskova I, et al. (2013) A familia case of alveolar capillary dysplasia with misalignment of pulmonary veins supports paternal imprinting of FOXF1 in human. Eur J Hum Genet 21: 474-477.

40. Michalskya MP, Arcac MJ, Groenmand F, Hammond S, Tibboeld D, et al. (2005) Alveolar capillary dysplasia: a logical approach to a fatal disease. J of Ped Surg 40: 1100-1105 